\title{
GAMBARAN PENGETAHUAN BIDAN TENTANG LOTUS BIRTH DI PUSKESMAS BARA-BARAYA, PUSKESMAS MAMAJANG, DAN PUSKESMAS BATUA MAKASSAR
}

Andi Sitti Rahma ${ }^{1}, \mathrm{Ni}$ 'mayani Syam² .

Fakultas Kedokteran dan Ilmu Kesehatan UIN Alauddin Makassar

\begin{abstract}
Abstrak
Lotus Birth merupakan metode persalinan dengan membiarkan tali pusat hingga terlepas sendiri secara alami. Metode persalinan ini masih menjadi kontroversi, baik dari segi manfaat maupun dari aspek tinjauan sosialnya, sehingga masih belum banyak diketahui dan dilakukan.

Penelitian ini merupakan penelitian observasional untuk mengetahui tingkat pengetahuan bidan di beberapa Puskesmas di Makassar tentang sejarah, manfaat dan pelaksanaan Lotus Birth. Sampel adalah bidan yang bertugas di puskesmas Bara-Baraya, Puskesmas Mamajang dan puskemas Batua yang berjumlah 31 orang.

Hasil yang diperoleh adalah sebanyak $54.84 \%$ responden dengan tingkat pengetahuan tentang Lotus Birth secara umum adalah kurang, 83,87\% tingkat pengetahuan kurang tentang sejarah Lotus Birth, 58.06\% tingkat pengetahuan kurang tentang manfaat Lotus Birth, dan 61,29\% tingkat pengetahuan kurang tentang pelaksanaan Lotus Birth.

Kesimpulan yang diperoleh adalah bahwa pengetahuan bidan tentang Lotus Birth masih kurang, baik pengetahuan secara umum, maupun pengetahuan tentang sejarah, manfaat dan pelaksanaan Lotus Birth.
\end{abstract}

Kata Kunci : Lotus Birth, Penundaan Pemotongan Tali Pusat.

\section{Pendahuluan}

Lotus Birth merupakan suatu proses persalinan yang tali pusat dibiarkan saja menempel di tubuh bayi hingga nantinya terlepas sendiri secara alami. Bermula dari seorang wanita bernama Clair Lotus Day meniru pendekatan holistik dari kera antropoid pada tahun 1974. Simpanse tidak memisahkan plasenta dari bayi yang baru lahir.(1)

Cara melakukannya tidak jauh beda dengan persalinan normal dimana setelah bayi lahir letakkan di perut ibu untuk melakukan IMD setelah itu perhatikan apakah plasenta sudah terlepas jika sudah lakukan peregangan dan pastikan plasenta lahir lengkap dan tidak ada selaput yang tertinggal, kemudian letakkan dalam wadah/baskom yang dialasi dengan underpad/popok alas ini harus diganti 1-2 kali sehari dan pastikan plasenta terkena udara agar terhindar dari bau busuk dan mempercepat proses pengeringan (2)

Lotus Birth memiliki beberapa manfaat yang hampir sama dengan penundaan pengkleman tali pusat untuk bayi dan ibunya, seperti jika tali pusat dibiarkan terus berdenyut sehingga memungkinkan terjadinya perpanjangan aliran darah ibu ke janin, bayi dapat tetap berada didekat ibunya lebih lama untuk bounding attachment, pemulihan tali pusat yang cepat (2-3 hari) dibandingkan normalnya jika segera dipotong dan mencegah bayi kehilangan $60 \mathrm{ml}$ darah yang setara dengan $1200 \mathrm{ml}$ darah orang 
dewasa yang sangat bermanfaat bagi bayi hingga tahun pertama kehidupannya (2)

Beberapa manfaat dilakukannya Lotus Birth di antaranya :

1. Tali pusat dibiarkan terus berdenyut sehingga memungkinkan terjadinya perpanjangan aliran darah ibu ke janin.

2. Oksigen vital yang melalui tali pusat dapat sampai ke bayi sebelum bayi benar-benar dapat mulai bernafas sendiri.

3. Bayi tetap berada dekat ibu setelah kelahiran sehingga memungkinkan terjadinya waktu yang lebih lama untuk bounding attachment.

4. Dr Sarah Buckley mengatakan :

"Bayi akan menerima tambahan 50-100ml darah yang dikenal sebagai transfusi placenta. Darah transfuse ini mengandung zat besi, sel darah merah, keeping darah dan bahan gizi lain, yang akan bermanfaat bagi bayi sampai tahun pertama."

Hilangnya $30 \mathrm{~mL}$ darah ke bayi baru lahir adalah setara dengan hilangnya $600 \mathrm{ml}$ darah untuk orang dewasa. Asuhan persalinan umum dengan pemotongan tali pusat sebelum berhenti berdenyut memungkinkan bayi baru lahir kehilangan $60 \mathrm{ml}$ darah, yang setara dengan $1200 \mathrm{ml}$ darah orang dewasa (2)

Manfaat dari Lotus Birth sangat banyak dan begitu bermanfaat dibandingkan dengan pemotongan tali pusat segera, tapi proses persalinan Lotus Birth ini di Indonesia terutama di Kota Makassar sendiri masih sangat lazim untuk dilakukan terbukti dari hasil pengambilan data awal masih lebih banyak bidan yang melakukan pengkleman tali pusat segera.

Pada pengambilan data awal di tempat yang akan diteliti hasilnya menunjukkan bahwa dari jumlah keseluruhan responden dari tiga tempat meneliti yaitu 31 bidan terdapat, 9 bidan melakukan penundaan pengkleman tali pusat pada masing-masing tempat, dan 22 bidan lainnya melakukan pengkleman tali pusat segera pada tempat masing-masing. Ini menunjukkan bahwa sekian banyak jumlah persalinan di setiap tempat tapi hanya beberapa bidan yang melakukan penundaan pengkleman dan pemotongan tali pusat.

Oleh karena itu, penulis tertarik melakukan penelitian tentang "Gambaran Pengetahuan Bidan Tentang Lotus Birth di Puskesmas Bara-Baraya, Puskesmas Mamajang dan Puskesmas Batua Makassar", karena penulis ingin mengetahui bagaimana pengetahuan bidan di beberapa Puskesmas Makassar tentang Lotus Birth. 


\section{Metode Penelitian}

Penelitian ini merupakan penelitian observasional, bertujuan untuk mengetahui tingkat pengetahuan bidan tentang Lotus Birth. Sampel adalah semua bidan yang bekerja di Puskesmas Bara-Baraya, Puskesmas Mamajang, dan Puskesmas Batua Makassar tahun 2013 berjumlah 31 orang.

Alat yang digunakan dalam penelitian ini adalah lembar kuesioner yang terdiri dari 24 pertanyaan untuk mengetahui sejauh mana pengetahuan Bidan tentang Lotus Birth. Dua puluh empat pertanyaan untuk mengetahui tingkat pengetahuan bidan yang meliputi, sejarah Lotus Birth, dan manfaat Lotus Birth dan cara pelaksanaan Lotus Birth.

Tingkat pengetahuan dikategorikan baik jika skor > 50, dan kurang jika memperoleh skor $\leq 50$.

\section{Hasil Penelitian}

Karakteristik responden dapat dilihat pada tabel 1, didapatkan mayoritas responden berusia di bawah 30 tahun sebanyak 51,61\%, tingkat pendidikan adalah DIII sebanyak $64.52 \%$ dan masa kerja 2-10 tahun sebanyak 54,84\%.

Tingkat pengetahuan responden tentang Lotus Birth dapat dilihat pada tabel 2 , diperoleh hasil hanya $45,16 \%$ responden yang memiliki tingkat pengetahuan baik, dan 54,84\% tingkat pengetahuan kurang.
Pengetahuan adalah merupakan hasil tahu dan ini terjadi setelah orang melakukan penginderaan terhadap suatu objek tertentu. Penginderaan terjadi melalui pancaindera manusia, yakni indra penglihatan, pendengaran, penciuman, rasa dan raba. Sebagian besar diperoleh melalui mata dan telinga (3)

Berdasarkan hasil wawancara yang dilakukan menunjukkan bahwa rendahnya pengetahuan responden tentang Lotus Birth disebabkan karena bidan yang telah bekerja kurang motivasi dan kesadaran lagi dalam dirinya untuk mendorong keinginannya tetap mencari tahu atau memperbaharui ilmunya seiring dengan berjalannya waktu yang dimana terus terjadi perubahan dan perkembangan terhadap ilmu kesehatan.

Faktor lain juga yang mempengaruhi pengetahuan responden menurut peneliti disebabkan oleh masih kurangnya bidan yang telah bekerja untuk meningkatkan sekolahnya ke jenjang lebih tinggi agar mendapatkan informasi tentang ilmu terbaru baik di bidang kesehatan maupun yang lainnya. Karena pendidikan salah satu faktor yang mempengaruhi pengetahuan Dengan pendidikan tinggi maka seseorang akan cenderung untuk mendapatkan informasi, baik dari orang lain maupun dari media massa. Semakin banyak informasi yang masuk semakin 
banyak pula pengetahuan yang didapat tentang kesehatan. (4) Tingkat pendidikan yang cukup akan memberikan kontribusi terhadap praktik kebidanan. Pendidikan bidan berpengaruh terhadap kinerja bidan karena semakin tinggi pendidikan yang ditempuh semakin banyak ilmu pengetahuan serta keterampilan yang dimiliki oleh bidan sehingga akan dapat membantu dalam meningkatkan kinerjanya dalam memberikan asuhan kebidanan kepada pasien.

Tingkat Pengetahuan responden tentang sejarah Lotus Birth dapat dilihat pada tabel 3, mayoritas responden tidak mengetahui tentang sejarah Lotus Birth, yaitu sebanyak $83.87 \%$.

Hasil penelitian yang dilakukan dengan metode wawancara kuesioner menunjukkan bahwa sangat sedikit responden (16.13\%) yang mengetahui tentang sejarah dari Lotus Birth, ini dapat dikarenakan banyak yang belum pernah sama sekali mendengar istilah ini sehingga mereka pun kurang memperluas pengetahuan seputar Lotus Birth.

Tingkat Pengetahuan responden tentang manfaat Lotus Birth dapat dilihat pada tabel 4, mayoritas responden tidak mengetahui tentang manfaat Lotus Birth, yaitu sebanyak $58.06 \%$.

Pengetahuan reponden tentang manfaat dari Lotus Birth sedikit lebih banyak yang mengetahuinya dari pada sejarahnya karena manfaat yang didapatkan dari metode Lotus Birth memang semuanya sama seperti manfaat dari penundaan pengkleman tali pusat yang memang sekarang telah mulai direalisasikan di lapangan. Seminar dan pelatihan penundaan pengkleman tali pusat memang sudah pernah diadakan, meski begitu tidak semua bidan pun mengetahui dan mengikutinya seperti di lihat dari hasil pengambilan data awal masih banyak yang belum melakukannya dalam proses persalinan.

Lotus Birth, seperti halnya penundaan pemotongan tali pusat, memberikan beberapa manfaat (5). Penundaan tali pusat berhubungan dengan peningkatan kadar ferritin pada bayi (6). Sebuah laporan kasus juga mengemukakan bahwa ibu yang memilih Lotus Birth berhasil meninggalkan rumah sakit tanpa ada infeksi dan penyulit apapun (4) Penundaan pemotongan tali pusat juga mememberikan beberapa keuntungan, antara lainpeningkatan kadar hemoglobin, mencegah terjadinya anemia pada bayi baru lahir, mengoptimalkan penyaluran oksigen ke bayi sehingga meningkatkan pertumbuhan otak bayi. (8) Waktu yang diperlukan untuk pelepasan tali pust pda persalinan dengan metode Lotus Birth adalah lebih singkat jika dibandingkan dengan persalinan konvensional, begitu 
pula dengan waktu pupus tali pusat dan bounding attachment dengan ibu (9)

Berbagai penelitian tentang manfaat Lotus Birth justru memberikan dampak negatif atau tidak memberikan perbedaan yang bermakna dengan persalinan konvensional. Sebuah penelitian mengemukakan tidak terdapat perbedaan antara penundaan klaim tali pusat dengan early klaim tali pusat. (10) Pernah dilaporkan adanya hubungan antara Lotus Birth dengan kejadi hepatitis neonatus idiopatik (11)

Tingkat Pengetahuan responden tentang pelaksanaan Lotus Birth dapat dilihat pada tabel 5, mayoritas responden tidak mengetahui tentang sejarah Lotus Birth, yaitu sebanyak $61.29 \%$.

Cara pelaksanaan Lotus Birth pun juga masih kurang responden yang mengetahuinya ini dikarenakan mereka sebagian belum pernah melihat atau merasa aneh dengan perawatan yang dilakukan dengan metode Lotus Birth ini. Namun, sebagian dari responden ada yang mengatakan ini merupakan tradisi orang dahulu yang berada di daerah-daerah perkampungan. Walaupun ada yang mengetahuinya itu dikarenakan telah mendapatinya di proses perkuliahan S-2 yang telah di jalaninya.

Lotus Birth merupakan metode baru yang dilakukan dengan cara tanpa memotong dan mengklem tali pusat sampai terlepas sendiri dari tubuh bayi (2). Hanya beberapa responden yang mengetahui ini, meskipun metode ini tergolong sangat baru dan tidak lazim didengar oleh tenaga kesehatan khususnya bidan, namun sebenarnya di kota-kota lain di Indonesia sudah di terapkan seperti di Yogyakarta dan di Bali.(12) Sarah Bukley, seorang dokter umum di Austalia juga memilih Lotus Birth pada kelahiran anakanaknya (13)

Pada beberapa negara, metode Lotus Birth ini masih menjadi kontroversi. Di legislatif Italia, cara ini tidak dapat disarankan baik dari sudut pandang ilmiah maupun logis / rasional. (14)

Dari penelitian ini maka dapat dilihat bahwa perlu adanya dorongan untuk semua bidan untuk terus memperbaharui ilmunya tentang Lotus Birth atau tentang ilmu-ilmu baru lainnya karena ilmu akan terus dikembangkan. Oleh karena itu, kita sebagai tenaga kesehatan sebaiknya mengikuti perkembangan ilmu yang terjadi agar kita juga dapat memberika pelayanan kesehatan yang lebih baik dan memadai bagi masyarakat serta kita juga dapat membagi informasi yang kita telah ketahui ke masyarakat luas. Sehingga, hasil dari penelitian ini dapat dijadikan sebagai bahan refrensi untuk penelitian 
lanjutan tentang sikap bidan dan ibu hamil terhadap Lotus Birth ini sendiri.

\section{Referensi}

1. Zinsser LA. Lotus Birth, a holistic approach on physiological cord clamping. Women and Birth. 2018;31(2):e73-6.

2. Riksani R. Keajaiban Tali Pusat dan Plasenta Bayi. Jakarta: Dunia Sehat. 2012;

3. Notoatmodjo S. Promosi kesehatan dan ilmu perilaku. Jakarta: Rineka Cipta. 2007;20.

4. Soekidjo N. Promosi Kesehatan Teori dan Aplikasi. Jakarta: Rineka Cipta. 2005 ;

5. Hutton EK, Hassan ES. Late vs early clamping of the umbilical cord in fullterm neonates: systematic review and meta-analysis of controlled trials. Jama. 2007;297(11):1241-52.

6. Eichenbaum-Pikser G, Zasloff JS. Delayed clamping of the umbilical cord: a review with implications for practice. J Midwifery Women's Heal. 2009;54(4):321-6.

7. Monroe KK, Rubin A, Mychaliska KP, Skoczylas M, Burrows HL. Lotus Birth: a case series report on umbilical nonseverance. Clin Pediatr (Phila). 2019;58(1):88-94.

8. Sari Nap. Karya Tulis Ilmiah Penundaan Penjepitan dan
Pemotongan Tali Pusat pada Bayi Ny. Y di BPM C. Retno Wahyuningsih Kecamatan Ayah Kab Kebumen.

9. Ratnasari L, Subekti EL, Wahyundari A, Utomo NEWAE. Pengaruh Persalinan Lotus Birth Terhadap Lama Pelepasan Plasenta, Lama Pelepasan Tali Pusat dan Keberhasilan Bounding Attachment. J Kebidanan. 2013;5(2).

10. Popat H, Robledo KP, Sebastian L, Evans N, Gill A, Kluckow M, et al. Effect of delayed cord clamping on systemic blood flow: a randomized controlled trial. J Pediatr. 2016;178:81-6.

11. Tricarico A, Bianco V, Di Biase AR, Iughetti L, Ferrari F, Berardi A. Lotus Birth Associated With Idiopathic Neonatal Hepatitis. Pediatr Neonatol [Internet]. 2017;58(3):281-2. Available from: http://dx.doi.org/10.1016/j.pedneo.201 5.11 .010

12. Skoko E. Memoirs of a Singing Birth. Lulu. com; 2012.

13. Buckley SJ. Lotus Birth: a ritual for our times. Midwifery Today. 2003;368.

14. Bonsignore A, Buffelli F, Ciliberti R, Ventura F, Molinelli A, Fulcheri E. Medico-legal considerations on "Lotus Birth" in the Italian legislative framework. Ital J Pediatr. 2019;45(1):4-9. 
Tabel 1

Distribusi Frekuensi Responden Beradasarkan Karakteristik

\begin{tabular}{llll}
\hline No & Karakteristik & \multicolumn{2}{c}{ Distribusi Frekuensi } \\
\cline { 3 - 4 } & & $\mathrm{n}$ & $\%$ \\
\hline 1 & Umur (tahun) & 16 & 51.61 \\
& $\leq 30$ & 7 & 22.58 \\
& $31-40$ & 7 & 22.58 \\
& $41-50$ & 1 & 3.23 \\
& $\geq 50$ & & \\
2 & Pendidikan & 1 & 3.23 \\
& D I & 20 & 64.52 \\
& D III & 5 & 16.13 \\
& D IV & 1 & 3.23 \\
& S I & 4 & 12.90 \\
& SII & & \\
& Masa Kerja (tahun) & & 19.35 \\
& $<2$ tahun & 6 & 54.84 \\
& $2-10$ tahun & 17 & 25.81 \\
\hline 10 tahun & TOTAL & $\mathbf{3 1}$ & $\mathbf{1 0 0 . 0 0}$ \\
\hline
\end{tabular}

Tabel 2

Tingkat Pengetahuan Responden tentang Lotus Birth

\begin{tabular}{llll}
\hline No & \multirow{2}{*}{ Tingkat Pengetahuan } & \multicolumn{2}{c}{ Distribusi Frekuensi } \\
\cline { 3 - 4 } & & $\mathrm{n}$ & $\%$ \\
\hline $\mathbf{1}$ & Baik & 14 & 45.16 \\
$\mathbf{2}$ & Kurang & 17 & 54.84 \\
\hline & TOTAL & 31 & 100.00 \\
\hline
\end{tabular}

Sumber : Data Primer

Tabel 3

Tingkat Pengetahuan Responden tentang Sejarah Lotus Birth

\begin{tabular}{llll}
\hline No & $\begin{array}{l}\text { Tingkat Pengetahuan tentang } \\
\text { Sejarah Lotus Birth }\end{array}$ & \multicolumn{2}{c}{ Distribusi Frekuensi } \\
\cline { 3 - 4 } & n & $\%$ \\
\hline $\mathbf{1}$ & Baik & 5 & 16.13 \\
$\mathbf{2}$ & Kurang & 26 & 83.87 \\
& TOTAL & 31 & 100.00 \\
\hline
\end{tabular}

Sumber : Data Primer 
Tabel 4

Tingkat Pengetahuan Responden tentang Manfaat Lotus Birth

\begin{tabular}{llcll}
\hline No & Tingkat & $\begin{array}{c}\text { Pengetahuan } \\
\text { Manfaat } \text { Lotus Birth }\end{array}$ & tentang & \multicolumn{2}{c}{ Distribusi Frekuensi } \\
\cline { 3 - 4 } & & $\mathrm{n}$ & $\%$ \\
\hline $\mathbf{1}$ & Baik & 13 & 41.94 \\
$\mathbf{2}$ & Kurang & 18 & 58.06 \\
& TOTAL & 31 & 100.00 \\
\hline & & \multicolumn{3}{c}{ Sumber : Data Primer }
\end{tabular}

Tabel 5

Tingkat Pengetahuan Responden tentang Pelaksanaan Lotus Birth

\begin{tabular}{lllll}
\hline No & Tingkat & $\begin{array}{c}\text { Pengetahuan } \\
\text { Pelaksanaan Lotus Birth }\end{array}$ & tentang & \multicolumn{2}{c}{ Distribusi Frekuensi } \\
\cline { 3 - 4 } & & $\mathrm{n}$ & $\%$ \\
\hline $\mathbf{1}$ & Baik & 12 & 38.71 \\
$\mathbf{2}$ & Kurang & 19 & 61.29 \\
& TOTAL & 31 & 100.00 \\
\hline
\end{tabular}

Sumber : Data Primer 